\title{
La CiUdad de Puntarenas y Sus Vehículos de MEMoria. ALGUNAS IMPLICACIONES DE TEORÍA EMERGENTE
}

City of Puntarenas and its memory's carriers. Some implications of Ground Theory

\author{
M.Sc. Luz Mary Arias Alpízar ${ }^{1}$ \\ Dr. Oriester Abarca Hernández,
}

\begin{tabular}{|l|l|}
\hline Recibido 8/X/2015 & Aprobado 15/XI/2015 \\
\hline
\end{tabular}

\section{Resumen:}

Se exponen resultados de una investigación realizada en la ciudad de Puntarenas sobre algunos vehículos de memoria colectiva (monumentos, placas y festividades) para derivar algunas consecuencias teóricas para la historiografía.

\section{Palabras claves:}

Puntarenas, memoria colectiva, monumentos, placas, festividades, teoría emergente.

\begin{abstract}
:
Results of research conducted in the city of Puntarenas on some collective memory vehicles (monuments, plaques and holidays) to derive some theoretical implications for historiography are presented.
\end{abstract}

\section{Keywords:}

Puntarenas, collective memory, monuments, plaques, holidays, Grounded Theory.

\section{Introducción}

Se realizó una investigación acerca de los vehículos de la memoria de la ciudad de Puntarenas, por la cual se entiende el área que va desde La Angostura hasta La Punta. Se identificaron 38 monumentos, esculturas y otras obras artísticas representativas y 93 placas, dispersas a lo largo de la ciudad de Puntarenas. Esto supone un total de 131 vehículos de memoria tangibles. Además, se identificaron 5 festividades, actividades o

\footnotetext{
${ }^{1}$ Profesora Asociada, Universidad de Costa Rica, luzmaryarias@gmail.com

${ }^{2}$ Profesor Catedrático, Universidad de Costa Rica, oriesterabarca@gmail.com
} 
conmemoraciones principales $^{3}$ que tienen lugar actualmente en diferentes momentos del año. Tales vehículos se han georreferenciado.

El artículo presenta algunas consideraciones teóricas a partir de los resultados de la investigación que se llevó a cabo, limitándose a una parte de los vehículos de memoria sobre los que se recopiló información por medio del trabajo de campo y en fuentes documentales. No se ha pretendido agotar todos los posibles tipos y formas de vehículos de memoria, sino hacer referencia a algunos de ellos, según se expone a continuación.

\section{Metodología}

Se aplicaron entrevistas con muestreo no probabilístico (muestreo intencional). El trabajo se complementó con el análisis de documentos como fuentes primarias. Se levantó un inventario de los monumentos y festividades de la ciudad de Puntarenas y, al efecto, se creó una base de datos digital. Cada monumento y placa se fotografió y se creó un archivo digital. Los monumentos, placas y festividades se georreferenciaron en un mapa digital. A partir de los datos así obtenidos se ha realizado un análisis cualitativo y se presentan algunas consideraciones planteadas como teoría emergente (Grounded Theory).

\section{Poder naturalizador de los vehículos de memoria. Construcción del pasado y del presente}

La memoria no refleja el pasado sino cómo se lo representa en el presente. Es imagen del pasado pero un hecho de la actualidad. En este sentido el poder naturalizador de la memoria colectiva cumple un papel normativo. Los vehículos de la memoria pretenden referirse al ser pero plantean en realidad un deber ser. Por medio de ellos se busca naturalizar un orden social construido. En consecuencia, la exactitud fáctica (esto es, si los hechos que se recuerdan son ciertos o no), deja de ser lo importante, para que pase a serlo el deber ser, naturalizado y naturalizador. Como representación del pasado, la memoria sirve para legitimar las representaciones del presente.

Cuando se preguntó a 20 personas (mayores de 50 años, que han vivido en Puntarenas desde su niñez) si saben desde cuándo se realizan las festividades de la Virgen del Mar, 7 respondieron que desde hace mucho tiempo pero no saben con exactitud; 5 respondieron que no lo saben del todo y 8 que desde 1913. Cuando se preguntó a estos últimos la fuente de la cual obtuvieron esa información (año 1913 como inicio), contestaron que lo leyeron o escucharon en un medio de comunicación (periódico, radio, televisión, blog).

A la pregunta: ¿conoce usted el motivo o causa por el que se empezaron a celebrar las festividades de la Virgen del Mar?, 15 respondieron que la razón fue que la Virgen del Carmen operó un milagro al salvar una embarcación que estaba a punto de naufragar y cinco dijeron que no lo saben. De los primeros solo 6 dieron algún detalle como el nombre el barco (El Galileo) o el nombre del propietario (Hermenegildo Cruz Ayala).

\footnotetext{
${ }^{3}$ Se trata las festividades de la Virgen del Mar, el desfile dedicado a Mora y Cañas, la carrera Sol y Arena, los carnavales y el Día de la Angostura.
} 
Cuando se les preguntó por la fuente de estos detalles, de nuevo respondieron que lo leyeron o escucharon en un medio de comunicación (periódico, radio, televisión, blog).

Sin embargo, la investigación documental, a partir de seis periódicos locales (El Correo de la Costa, El Espartano, El Horizonte, El Pacífico, El Puntarenense, El Viajero) de los años 1913-1917, produjo datos distintos a los que actualmente se presentan en la prensa o en internet: las festividades se empezaron a celebrar en $1914^{4}$ y no en 1913; el fundador fue el presbítero José Daniel Carmona, quien fue cura de

${ }^{4}$ En una carta dirigida a los feligreses, de fecha 7 de junio de 1916, el presbítero José Daniel Carmona expresaba: "Por tercera vez tengo la dicha de celebrar con vosotros esta simpática fiesta religiosa que hace dos años fundé para la gloria de Dios, de la Virgen del Carmen, patrona de los navegantes y vuestra propia felicidad" (Carmona, 1916, p. 1). La cursiva no aparece en el original.

Con anterioridad, en una carta dirigida al Director del periódico El Correo de la Costa y de fecha 24 de julio de 1914, el mismo Carmona manifestaba: "El próximo domingo [26 de julio de 1914] celebraré la fiesta de Nuestra Señora del Carmen, Patrona de los marinos. Como además del acto religioso, esta fiesta revestirá un carácter netamente local que dará gran movimiento a este puerto, deseo darle desde su fundación toda la solemnidad posible con asistencia de nuestras autoridades, y en este concepto me permito invitarle. Dichas autoridades y representantes de Corporaciones sociales irán en una gasolina aparte" (Carmona, 1914, p. 4). La cursiva no aparece en el original.

En un artículo de 1914, Francisco Ruiz expresaba su opinión sobre las festividades que pretendía realizar el padre Carmona: "Se trata de hacer una fiesta en honor de la Virgen del mar; si hay un lugar en el mundo donde se necesite fe, es en esa inmensidad de agua que con sus bravuras y placideces hace conocer al hombre el poder sobrenatural que nos domina... La fiesta que para el próximo domingo 26 ha iniciado el Padre Carmona y que secundarán todos los habitantes de Puntarenas, no es fiesta de bacanal y desacato, es una fiesta que dará al marino lo que hoy no tiene: FE... Grande será la fiesta porque grande es la idea" (Ruiz, 1914, p. 1). La cursiva no aparece en el original, pero sí las mayúsculas.

El Correo de la Costa, en su edición del 13 de julio de 1914 expresó: "El Pbro. Carmona, Cura de esta Parroquia, está actualmente empeñado en llevar a la práctica una bonita fiesta religiosa, no acostumbrada en Costa Rica, pero sí en muchos puertos europeos. Se trata de celebrar la festividad de la Virgen del Carmen, Patrona del mar. El Padre ha lanzado la idea, que ha sido acogida con mucho entusiasmo por todos los propietarios de embarcaciones.

La festividad sería así: misa en la playa, estando todas las embarcaciones que concurran ancladas lo más cerca posible de la orilla; plática explicativa del acto; bendición de las embarcaciones; procesión por el mar, llevando la Virgen. Otros muchos detalles harán que la fiesta resulte, además de moralizadora, bonita.

Don Serafín Saravia ha ofrecido una de sus embarcaciones para llevar a la Virgen, la cual adornará convenientemente. Esta fiesta tiene sus ventajas: la significación moral de ella, la exhibición de lo que pudiéramos llamar nuestra marina mercante, y la aglomeración de gentes de la costa, que algún movimiento darán al comercio.

Seguramente este año, por la premura del tiempo, y por ser desconocida la festividad, no estará ésta completamente animada; pero si en los siguientes años se sigue la costumbre, llegará a ser ésta una de las más hermosas festividades religiosas que celebremos aquí” (La Virgen del Carmen Patrona del Mar Fiesta Religiosa, 1914, p. 1). La cursiva no aparece en el original.

El Correo de la Costa, en el editorial de su edición del 27 de julio de 1914, un día después de la primera procesión marítima celebrada en Puntarenas en honor de la Virgen del Mar, manifestó: "Hacía apenas dos o tres semanas que se había anunciado por el estimable Cura de esta Parroquia, el Presbítero señor Carmona, que este día iba a celebrar una fiesta en el Estero, en homenaje de nuestra Señora del Carmen, Patrona, como es sabido, de los hombres de mar...

El que esto escribe, tomando en cuenta la indiferencia con que se ve aquí por el sexo de barba todo lo que tiene alguna relación con la Iglesia, se imaginó que ésta sería una de tantas fiestecillas, sin animación, y que apenas si dejaría un débil recuerdo para el día siguiente. Pero ¡quiá! Toda suposición acerca de su fracaso, fue desmentida por modo elocuente con la más hermosa fiesta que los puntareneños habrán presenciado en su vida" (Festival grandioso, 1914, p. 1). 
Puntarenas en esa época y no se encontró una referencia al milagro ni al señor Cruz Ayala como "fundador"5. Esto sugiere que un vehículo de la memoria, originado en el segundo decenio del siglo XX, ha sido reconstruido posteriormente y en la actualidad el contenido de lo recordado no coincide plenamente con los hechos históricos que se pretenden recordar. Instrumentalmente, en esta reconstrucción de la memoria ha jugado un papel muy importante tanto la prensa como internet.

El caso de los cañones, que se ubican actualmente al costado sur de la Casa de la Cultura y en el sector oeste de la Capitanía de Puerto, también apoya nuestros planteamientos de teoría emergente. Al mismo grupo se le preguntó si sabe por qué hay cañones en esos sitios. La casi totalidad (18 personas) respondió que no sabe y solo una persona afirmó que habían sido dejados por los piratas. Al preguntársele a esta si sabía cuándo tuvo lugar el ataque y cuál fue el origen de la información, respondió a lo primero que no sabía y a lo segundo que era una historia que se contaba en su familia paterna (se la había oído contar a su abuelo). Otra persona respondió que era artillería de la II Guerra Mundial, usada por los estadounidenses, pero que desconocía cómo llegó a la ciudad de Puntarenas y tampoco pudo identificar la fuente de dónde había tomado esa información, pues no lo recordaba.

Si bien los piratas atacaron Esparza en el último tercio del siglo XVII y merodearon, en ocasiones, por el golfo de Nicoya (Fernández Guardia, 1991, pp. 87-91, 105-109), no se tiene conocimiento de que alguna vez hubieran realizado un ataque a Puntarenas en tiempos de la colonia - pues como poblado y puerto, no existió sino muy tardíamente, a partir de la segunda mitad del siglo XVIII- ${ }^{6}$, aunque sí recientemente -pero no han hecho uso del tipo de cañones sobre los que se consultaba- (Piratas atacaron a pescadores cerca de la Isla Chira de Puntarenas, 2008; Banda de piratas asaltó barco pesquero que zarpaba de Puntarenas, 2012; Garita, 2012; 10 piratas atemorizan a los pescadores ticos, 2012). La presencia de los cañones puede tener diferentes orígenes. Al utilizar como fuente los mensajes de jefes de Estado y de presidentes de la República (recopilados por el historiador Carlos Meléndez), se determinó que la primera vez que en ellos se hace mención de Puntarenas en relación con una situación bélica, es en el mensaje de José María Alfaro, de 1843, en el que se refiere a la permanencia de la "armada" de Francisco Morazán -comandada por el general Sageten las aguas de ese puerto. Expresó Alfaro (en Meléndez Chaverri, 1981a) que "hubo de retirarse aquella facción no sin cometer antes el acto de procacidad de saltar a tierra a arrebatar víveres que el gobierno les había negado" (p. 131).

\footnotetext{
${ }^{5}$ De acuerdo con las diferentes versiones orales y escritas, posteriores al decenio de 1910, fue él quien tuvo la iniciativa de realizar las festividades de la Virgen del Mar en la ciudad de Puntarenas.

${ }^{6}$ Según González Víquez (1933), se menciona por primera vez a Puntarenas, como puerto, en 1765 y afirma que "el informe del Director de la renta de tabacos del Reino, de 1772, y otros posteriores, hablan de él, con la particularidad de que, según el Gobernador Acosta (informe de 1804. Doc. X, p. 202), el puerto de la Caldera, que describe, 'es conocido hoy con el nombre de Punta de Arenas'. Eso significa que Caldera, en realidad, había sido abandonado, sin que haya campo a duda porque el Gobernador agrega que 'en él pueden entrar barcos de todo porte, pues en toda su extensión hay de 15 a 25 brazas de agua, su fondeadero al abrigo de los vientos y el fondo de arena', descripción que no correspondería a Caldera aisladamente” (pp. 7-8).
} 
También menciona Alfaro (en Meléndez Chaverri, 1981a), en su mensaje de 1843, el reclamo "que vino a hacer hasta Puntarenas en el Buque de Guerra Inglés 'Campeón’ su comandante el Sr. R. Bayron” (p. 143). El reclamo se presentó por supuestos perjuicios causados a los súbditos británicos en la Federación de Centroamérica. Y agrega: “este reclamo y la manera amenazante, con que se efectuó son nuevos testimonios de lo urgente que es tener un gobierno nacional respetable, para que no seamos el juguete de cualquiera que se halle con fuerza para abusar" (Alfaro, en Meléndez Chaverri, 1981a, p. 143, pues el pago lo había hecho el Gobierno sin que se hubiera presentado ningún documento que fundamentara el reclamo de los súbditos británicos, sin cumplir

el modo prevenido por las leyes y principios que se observan en este género de negocios; sin que la parte dudosa interviniese en la liquidación, habiendo sido todo esto hecho por solo el Sr. Cónsul [británico para Centroamérica] Chatfield quien también ha distribuido por sí y ante sí la suma que cada Estado se ha visto obligado a satisfacer, por debilidad respecto del coloso inglés. (Alfaro, en Meléndez Chaverri, 1981a, p. 143)

Se vuelve a relacionar a Puntarenas con hechos bélicos en el mensaje de José María Montealegre de 1861. Se refiere al levantamiento efectuado en Esparza por Arancibia el 15 de setiembre de 1860, al que siguió, dos días después (el 17 de setiembre de 1860), el desembarco de Juan Rafael Mora en Puntarenas. Según expresó Montealegre (en Meléndez Chaverri, 1981b):

Sabéis ya el sangriento desenlace del atentado que en el mes de setiembre próximo pasado se perpetró. Entre los deberes que como Presidente de la República tenía, y los sentimientos de moderación y humanidad que jamás he desmentido, cedí a una imperiosa necesidad; cedí a las exigencias de la ley, y a mis obligaciones como hombre público; empero vi con dolor, no sólo la preciosa sangre y sacrificios que la pacificación de Puntarenas costara, sino también el inevitable castigo impuesto a los caudillos de la facción. (pp. 15-16)

Como es sabido, se trataba del enfrentamiento entre dos facciones de la élite cafetalera costarricense (sobre la coyuntura de 1860 véase Fallas Santana, 2004, 2008), que, sin embargo, rebasó los intereses meramente domésticos. Así, la prensa estadounidense informó de los hechos. Según el Sacramento Daily Union, en su edición del 26 de octubre de 1860:

IMPORTANTE DESDE COSTA RICA.- Las noticias más importantes proceden de Costa Rica. El presidente legítimo, Juan Rafael Mora, ha regresado en el vapor Columbus de El Salvador y ha desembarcado en Puntarenas, donde ha sido recibido con los brazos abiertos por la población, lugar del cual tomó posesión cuando el vapor zarpó, con una fuerza de trescientos hombres bajo el mando de los Generales Cañas y Mora.

La ciudad está bien atrincherada y La Angostura, un paso que está como a media legua del puerto, está bien fortificada. La impresión es que Mora será capaz de reinstalarse en la Presidencia, pero sin duda causará mucho derramamiento de sangre, a no ser que de hecho la población del interior se declare simultáneamente en contra del usurpador Montealegre ${ }^{7}$. (Important from Costa Rica, 1860, p. 2)

\footnotetext{
${ }^{7}$ Las versalitas son del original. La traducción del inglés es nuestra.
} 
Y el New York Times, en su edición del 8 de octubre de 1860, así como el Panama Star \& Herald, en su edición del 27 de octubre de 1860, publicaron el último discurso que pronunció el presidente Mora, antes de su trágico asesinato ${ }^{8}$ :

JUAN RAFAEL MORA a sus conciudadanos.

Costarricenses:

Cuando en abril próximo pasado, os hice saber las razones que me impidieron ayudaros a sacudir el yugo de vuestros opresores, no pude prever la magnitud que hoy alcanza vuestro sufrimiento.

Nunca intenté abandonaros; solo os pedí esperar y trabajar por el bien del país, porque pensé que el tiempo restablecería la paz interna, sin que mi presencia en esta República fuera necesaria.

Desafortunadamente, estaba equivocado. Más de un año ha transcurrido desde los hechos del 14 de agosto. Por tanto, vuestros gobernantes han tenido tiempo suficiente para hacer algo en beneficio del país, si hubieran sido capaces o lo hubieran querido.

Pero lejos de ello, el pasado año solo ha sido para Costa Rica una página de lágrimas y dolor. El pueblo castigado y oprimido, los puertos cerrados al comercio, el Tesoro Nacional casi en bancarrota; en fin, vuestro país vendido, ofrecido indirectamente a los filibusteros. Y todo esto sin considerar la miseria general, el desaliento y la desesperanza que hacen más pesado vuestro trabajo y perturban vuestro reposo.

Ha llegado ya el día de que esto se acabe. Vuestros frecuentes llamados y el regreso a América Central del filibustero Walker, nos ha movido, a los Generales Cañas y Mora y a mí, a sacrificar nuestra tranquilidad, por la independencia y el bienestar de Costa Rica.

¡Soldados, a las armas! Que la sangre derramada en Nicaragua, Santa Rosa y el río San Juan, no sea estéril; venid a uniros con nosotros, y no tendréis nada qué temer del porvenir.

No es el deseo de venganza lo que guía mis pasos, la clemencia se conforma mejor a mis sentimientos; así es que olvidaré los errores de aquellos que, engañados, sirvieron a los traidores; pero tened presente que seré inflexible con aquellos que, de hoy en adelante, no respondan al llamado de su agónico país, y haré que todo el vigor de la ley caiga sobre aquellos que, de la manera que sea, presten ayuda al enemigo común.

¡A las armas, costarricenses! Apresuraos a uniros con nosotros y a romper vuestras cadenas al grito de “ $i$ VIVA

COSTA RicA’!

JUAN R. MORA.

Punta Arenas, 17 de setiembre 1860..$^{9}$ (The New York Times, 1860; Panama Star \& Herald, 1860)

Días después el New Orleans Commercial Bulletin, lacónicamente informó:

Costa Rica - Derrota del Gen. Mora.- Las fuerzas del gobierno de Costa Rica han atacado y derrotado completamente a las tropas comandadas por el Gen. Juan Rafael Mora, ex-Presidente de esa República. Los

\footnotetext{
${ }^{8}$ Y que, hasta donde sabemos, está inédito en español.

${ }^{9}$ Las versalitas son del original. La traducción del inglés es de Oriester Abarca Hernández. El texto se ha reconstruido a partir de ambas publicaciones, considerando, además, el léxico y estilo discursivo de Mora Porras en sus mensajes presidenciales, proclamas y discursos -especialmente la Proclama de San Salvador, de enero de 1860, según el texto que aparece en Durán Luzio (2011, pp. 55-56)-.
} 
Generales Mora y Cañas y otros fueron fusilados por los vencedores ${ }^{10}$. (Costa Rica. Defeat of Gen. Mora, 1860, p. 2)

Y el Staunton Spectator, de Virginia, en su edición del 30 de octubre de 1860, expresó:

Mora asumió su destino con valentía. El pelotón de fusilamiento estuvo con sus mosquetes a no más de diez pies de distancia de él y, sin embargo, las cinco balas en su cuerpo no lo mataron. "Dispárenme de nuevo, caballeros"-dijo-, "y finalícenme". Se opuso a que le vendaran los ojos, pero permaneció calmo frente a sus ejecutores. Su cuerpo, así como el de Cañas, fue arrojado a un hoyo en la arena; ambos, con las ropas que llevaban puestas cuando los asesinaron. Cañas estaba encendiendo de nuevo su cigarrillo en el momento que sintió el plomo en su corazón. Fue fusilado al pie del monumento erigido en su honor por los muchos servicios que había prestado a Costa Rica, en la Plaza de Punta Arenas ${ }^{11}$. (The Bravery of Two Noted Fillibusters, 1860, p. 1)

La presencia de los cañones no se ha asociado, en la memoria colectiva puntarenense, a aquella batalla de La Angostura -a pesar de que en ella se utilizaron varios-, sino más bien a la Campaña Nacional. En una publicación de 1915, el periódico El Espartano sugirió, como “algo que podría ser un adorno bellísimo para la población", lo siguiente:

Hace varios años fueron botados en la playa unos cuantos cañones antiguos, los que se conservaban en el patio del cuartel de armas, desde el tiempo de la campaña nacional. Estos grandes pedazos de hierro, que de nada sirven en nuestra hermosa playa, vendrían a ser un hermoso adorno, si se colocaran en asientos de calicanto u otra sustancia. Es una cosa que costaría sumamente barata, y en cambio sería una novedad, para los numerosos visitantes del puerto.

Queda lanzada la idea, para que si la Municipalidad lo tiene a bien, proceda, tarde o temprano a dicha obra. (Algo que podría ser un adorno bellísimo para la población, 1915, p. 4)

Y el periódico El Viajero, en 1917 informó que "en el tren de la tarde de ayer, llegaron dos piezas más de artillería, con su correspondiente número de oficiales y soldados. Suponemos ese armamento destinado al servicio de honores militares" (Más cañones, 1917, p. 1).

No resultó posible establecer el origen de los cañones por vía de fuentes orales.

Lo anterior apunta a que algunos vehículos de memoria sobreviven pero se desligan de los hechos por los cuales se originaron. Nadie en el presente, o muy pocos, saben por qué esos vehículos existen. Algunos de los vehículos de memoria que sobreviven solo existen como sustrato material, sin poder simbólico alguno y, en consecuencia, son el resultado de path dependency. El olvido es necesario para la memoria, como herramienta de reconfiguración del pasado y de representación del presente.

\footnotetext{
${ }^{10}$ Las versalitas son del original. La traducción del inglés es nuestra.

${ }^{11}$ La traducción del inglés es nuestra.
} 
El caso de las placas es ilustrativo. Se lograron identificar 93 placas, las cuales se ubican en distintos puntos de la lengüeta de arena. Se realizaron 40 entrevistas in situ, en 4 distintas placas (10 entrevistas por placa), a transeúntes que manifestaran ser habitantes de la ciudad por al menos los últimos diez años. Sólo un doce por ciento de las personas pudieron dar algún dato sobre la placa o sobre el significado de su contenido. Y en la casi totalidad de los casos por tratarse de contenidos ampliamente conocidos u obvios, tal como la placa conmemorativa del centenario del nacimiento de José Martí y que fue puesta por la Municipalidad de Puntarenas en 1953 para, además, identificar la calle que lleva el nombre del poeta cubano ${ }^{12}$. Otro ejemplo en este sentido es el de la placa dedicada a Juanito Mora ${ }^{13}$.

En cambio, cuando se preguntó a los informantes sobre una placa colocada en 1950 y que identifica una avenida con el nombre "Doctor Sergio Fallas Badilla"14, todos declararon no saber quién fue la persona que por ese medio se honra. El nombre del Dr. Fallas Badilla también aparece en una placa, colocada el 29 de abril de 1986 por la Municipalidad de Puntarenas, que expresa:

En el corazón de los Puntarenenses perdurará en forma imperecedera el recuerdo de quienes lo dieron todo por el pueblo. A ellos, como homenaje la Municipalidad los declara benefactores e hijos ilustres del cantón Central de Puntarenas ${ }^{15}$.

Y a continuación la placa enlista a los presidentes Juan Rafael Mora Porras, Jesús Jiménez Zamora, Tomás Guardia Gutiérrez, Rafael Iglesias Castro, Ricardo Jiménez Oreamuno, Cleto González Víquez, León Cortés Castro, Rafael Ángel Calderón Guardia y Mario Echandi Jiménez; al general José María Cañas y a los señores Francisco de Paula Amador, Pbro. José Daniel Carmona, Uladislao Guevara Pérez, Josefa Pons Quesada, Manuel Obando Valdés, Sergio Fallas Badilla, Manuel Madriz Pinto, José Moreno Arellano, Eduardo Angulo Obando, Augusto Bolaños Víquez, Ovidio Salazar Salazar, Carlos L. Padilla Rodríguez, Carlos Luis Fallas Sibaja, Rafael A. Rodríguez G., Emiliano Odio Madrigal, Antonio Retana Cruz, Carlos Biolley Riotte, Rafael París Steffens, Gonzalo Lizano Ramírez, Juan R. Sotomayor V., Carlos L. Rodríguez H., Stewart Heigold Stuart y Fray Casiano de Madrid. De la lista la gran mayoría (80 por ciento) de los entrevistados no tuvo ningún problema en identificar a los presidentes, al general Cañas y a Fray Casiano de Madrid, pero un 95 por ciento dijo desconocer quiénes eran los demás "benefactores e hijos ilustres del cantón". Respecto a este último conjunto de homenajeados, la placa evidentemente había fallado como vehículo de la memoria colectiva de los habitantes de la ciudad de Puntarenas, a pesar de la promesa que la misma placa hace al respecto, en su literalidad. Es posible suponer que los personajes históricos que sí fueron recordados por los

\footnotetext{
${ }^{12}$ La placa se ubica en entre la avenida 1 y la avenida Central, al costado oeste de la Catedral; la placa se localiza en la paredes exteriores al edificio, por la entrada.

${ }^{13}$ Ubicada en la avenida 1, del Gimnasio Municipal 100 metros al este y de los Tribunales de Justicia 100 metros al norte; costado norte del Parque Mora y Cañas.

${ }^{14}$ Ubicada en avenida 1, del Gimnasio Municipal 100 metros al este y de los Tribunales de Justicia 100 metros norte, esquina sureste del Parque Mora y Cañas.

${ }^{15}$ La placa se ubica en avenida 1, del Gimnasio Municipal 100 metros al este y de los Tribunales de Justicia 100 metros al norte. La placa se localiza al costado norte de la cancha de básquetbol.
} 
entrevistados, fueron conocidos por estos últimos por otros vehículos de memoria de más amplio alcance que solo el local, tales como los libros de texto escolares o la existencia de organizaciones locales como el Hogar Monserrat, fundado y dirigido durante muchos años por Fray Casiano y aún en operación.

Lo anterior apunta a que las diversas memorias colectivas se pueden superponer, yuxtaponer, reforzar mutuamente o contradecir, creando sincretismos y generando perspectivas -a veces abigarradas, pero siempre múltiples- de la realidad.

De igual manera, en un mismo vehículo de memoria pueden confluir distintas representaciones y pretensiones de legitimidad, de distintos individuos y grupos. Así, cuando un miembro de la comunidad china participaba en el decenio de 1910 en la procesión marítima de la Virgen del Carmen, con una embarcación bellamente adornada, más que rendir tributo a la advocación mariana o hacer un ejercicio de su catolicismo, podía estar buscando la integración y aceptación en la comunidad en la que era inmigrante ${ }^{16}$. Cabe considerar el contexto histórico en que esto ocurría, pues, en el primer cuarto del siglo XX, algunos acusaban a los inmigrantes chinos de no aportar a la producción nacional, especialmente a la agrícola en un país con vocación para ella, y dedicarse principalmente al comercio.

A una memoria colectiva puede contraponerse una contramemoria, como política de olvido. Otros subsisten, también por path dependency, pero su poder simbólico se ha dirigido a naturalizar nuevos contenidos y significados, de construcción reciente. Esto es así porque la memoria es socialmente construida y es dinámica (no se conserva).

Además, la memoria colectiva puede ser construida desde arriba o desde abajo. La religiosidad popular puede ser engañosa, a este respecto, pues puede parecer una construcción desde abajo, por ser practicada por las clases de menor poder o rango social, pero su construcción puede no haber tenido origen en esos grupos. Las festividades de la Virgen del Carmen son un ejemplo en este sentido, dado que fueron concebidas desde la jerarquía eclesiástica y su organización, en los primeros años que se han estudiado, estaba a cargo de miembros de la élite económica y política; sin embargo, también asumió el carácter de una festividad que se expresado como religiosidad popular.

La memoria colectiva es ante todo un código semántico de memorización y de rememoración; también es una jerarquía de valores que estructura un discurso en el pasado mientras lo arraiga en el presente. Así, en Puntarenas, mientras la oligarquía cafetalera erigía la figura de Juan Santamaría como héroe de la campaña nacional, el recuerdo de Juanito Mora y del general José María Cañas, no se perdió sino que, a contracorriente

\footnotetext{
${ }^{16}$ Por ejemplo, en las festividades de la Virgen del Mar de1917, "la lanchita de don José Apuy, representaba un hermoso Cisne tan hábilmente imitado, que parecía natural, y era tanto más semejante, cuanto que al correr veloz por el tranquilo estero, daba la idea de un cisne real y verdadero, nadando sobre la superficie del agua. Felicitamos al amigo Apuy por tan meritorio y artístico trabajo" (Las fiestas de la Virgen del Mar, 1917, p. 1).
} 
de las tendencias que prevalecían a nivel nacional ${ }^{17}$, la memoria de Mora, así como la de Cañas, apuntalaron el sentido de identidad local. Según González Vásquez, en la provincia de Puntarenas tres escuelas llevan el nombre del presidente Mora (en el poblado El Carmen del distrito Biolley, cantón de Buenos Aires; en Barranca y en el barrio El Cocal de la ciudad de Puntarenas), existe un barrio en el distrito de Barranca que se denomina Juanito Mora y

un emblemático parque en la ciudad cabecera recuerda el sitio en que fueron fusilados Mora y Cañas, el 30 de setiembre y el 2 de octubre de 1860, respectivamente. Asimismo, cada 30 de setiembre hay un desfile, conocido como de la Conmemoración Próceres Mora y Cañas, al que concurren bandas musicales, de centros educativos nacionales y extranjeros, que transitan a lo largo del extenso Paseo de los Turistas. (González Vásquez, 2010, p. 105).

El reconocimiento que la Asamblea Legislativa de la República de Costa Rica otorgó por medio de la Declaración de Libertador y Héroe Nacional a Juan Rafael Mora Porras, (República de Costa Rica, 2010) aprobada el 16 de setiembre de 2010, ya había sido realizado casi cien años antes por los obreros y la juventud. En el parque Mora y Cañas se ubica una placa, que expresa:

A la memoria de los beneméritos de la Patria generales Juan Rafael Mora y José María Cañas muertos en este lugar el 30 de setiembre y 2 de octubre respectivamente el año 1860 - La juventud y los obreros de Costa Rica les tributan este homenaje - 8 de diciembre de 1918.

Otra placa, colocada bajo su busto en 1960, en ese mismo parque, por la Municipalidad de Puntarenas, expresa:
Presidente
Juan Rafael Mora
Benemérito de la Patria
Reconocimiento del
Pueblo de Puntarenas
Municipalidad de Puntarenas
Año del Centenario
$1960^{18}$

También en ese parque hay un busto del general Cañas y una placa que lo acompaña, de esa misma fecha y, mutatis mutandis, con el mismo texto.

\footnotetext{
${ }^{17}$ Sobre los intentos de recuperar la memoria de Mora Porras desde el siglo XIX y la renuencia oficial, véase Díaz Arias (2014).

${ }^{18}$ La placa se ubica en avenida 1, del Gimnasio Municipal 100 metros al este y de los Tribunales de Justicia 100 metros al norte, en el costado norte del parque Mora y Cañas.
} 
El recuerdo de Mora en la memoria colectiva puntarenense ha sido una construcción tanto desde arriba como desde abajo. Los habitantes de la ciudad lo recuerdan tanto como la élite política y ello se refleja en vehículos de memoria como el proyecto que el diputado puntarenense Óscar Solera Solera presentó en $1960{ }^{19}$. Este proyecto proponía:

ARTÍCULO $1^{\circ}$ - Se declara el próximo 30 de setiembre de 1960, Fecha Nacional y Día Feriado. ARTÍCULO $2^{\circ}$ - Las Municipalidades del país podrán destinar fondos para conmemorar el día 30 de setiembre de 1960, al cumplirse el primer centenario de la muerte del ex-presidente de la República don Juan Rafael Mora y del General José María Cañas, héroes de la Campaña Nacional de 1856 y Beneméritos de la Patria, para lo cual necesitarán la aprobación de la Contraloría General de la República, a cuyo fin se tendrá por reformado el artículo $2^{\circ}$ de la Ley de Hacienda Municipal $\mathrm{N}^{\circ} 180$ de 28 de agosto de 1923 y su correspondiente reforma $\mathrm{N}^{\circ}$ 1976 de 27 de octubre de 1955.

ARTÍCULO $3^{\circ}$ - La Municipalidad de Puntarenas podrá destinar, previa aprobación de la Contraloría General de la República, hasta la suma de diez mil colones $(\not 10.000,00)$ para conmemorar esa Fecha Nacional con la debida solemnidad.

ARTÍCULO $4^{\circ}$ - Todos los colegios de Enseñanza Media del país están obligados a enviar representaciones a los desfiles que se celebrarán en la ciudad de Puntarenas el día 30 de setiembre de 1960, y el Instituto del

${ }^{19}$ En la exposición de motivos Solera Solera expresó: "En la vieja Puntarenas de 1860 bajo un árbol de jobo, a las 6 de la mañana del día 30 de setiembre, una descarga de odio, que no de fusilería, cegó la vida del estadista don Juan Rafael Mora. Dos días después, a la misma hora y en el mismo sitio, una descarga igual acabó con la existencia de quien había sido su hermano, tanto en la vida como en la gloria; el General José María Cañas.

A Puntarenas, mi ciudad natal, le tocó recoger en el regazo tibio de su tierra, sembrada de manglares y bañada por las olas del mar, los despojos sagrados de ambos esclarecidos ciudadanos, que supieron levantar el nombre de la patria, con el esfuerzo de sus ideas y el empeño de sus espadas fulgurantes, a la cima de gloria en que hoy descansa, para contemplación de nacionales y extranjeros.

Fue gracias a la generosa intervención de los señores Juan Jacobo Bennefill, Jules Rosat y Santiago Constantine, que el General Blanco accedió a quitar los cadáveres a la soldadesca infame, que quería lanzarlos al mar, y fueron ellos mismos quienes, en rústicos ataúdes, fabricados con sus propias manos, bajo las sombras de la noche, los llevaron en una lancha por el Estero, acompañados de los señores Nanne, Farrer y el Capitán Roger, para darles sepultura en el cementerio de Aldea, donde reposaron por seis años, cubiertos por el olvido y la temerosa ingratitud de sus contemporáneos.

Don Juan Jacobo Bonnefill, dando a los costarricenses un hermoso ejemplo de lo que es un alma noble, que no puede olvidarse de sus amigos, no importa cuán adversas sean las circunstancias, a su propia casa de habitación en San José, donde les rindió por muchos años, el homenaje de su más profunda veneración. En 1885, presintiendo el fin de sus días, el señor Bennefill arregló, casi sigilosamente, el traslado de los restos al Cementerio General, donde fueron sepultados el día 13 de enero.

Pero la patria no podría olvidar para siempre a sus hijos predilectos, tal como lo presintiera el prócer Mora en su carta de despedida a su esposa, la augusta matrona doña Inés Aguilar de Mora, escrita pocas horas antes de su fusilamiento: 'y la Patria, aunque cruel conmigo, tal vez no será lo mismo con mis hijos, pues, vendrá tiempo en que valgan algo los pocos servicios que le he prestado en casi la mitad de mi vida'.

A los 100 años de la muerte del ex-presidente don Juan Rafael Mora y del General José María Cañas, Costa Rica venera su memoria como la de los más altos y eximios próceres de su existencia republicana.

Ahora, con motivo de acercarse la fecha en que habrá de conmemorarse el primer centenario de su muerte, me cabe a mí, el más humilde de los puntarenenses, el alto honor de presentar a conocimiento de la Asamblea Legislativa el siguiente proyecto de ley" (Costa Rica venera la memoria del don Juan Rafael Mora y del General José María Cañas, fusilados en Puntarenas. El primero el día 30 de setiembre de 1860 y el segundo el 2 de octubre de 1860, 1960, p. 13). La cursiva es el original. 
Ferrocarril Eléctrico al Pacífico a proveer el transporte de esas delegaciones en forma gratuita. Los Supremos Poderes de la República también se harán representar en esas ceremonias.

ARTÍCULO $5^{\circ}$ - Esta ley rige a partir de su publicación. (Costa Rica venera la memoria del don Juan Rafael Mora y del General José María Cañas, fusilados en Puntarenas. El primero el día 30 de setiembre de 1860 y el segundo el 2 de octubre de 1860, 1960, p. 13)

El proyecto recibió el apoyo de la Asamblea Legislativa y se convirtió en ley de la República (República de Costa Rica, 1960), pero en su ejecución algunos estudiantes se quejaron de discriminación ${ }^{20}$, mientras Claro González (1960), en una publicación en el Diario de Costa Rica, calificó la conmemoración del centenario de la caída de los próceres como "un verdadero apoteosis" (sic) (p. 14).

Puntarenas se convirtió en el centro principal de las conmemoraciones dedicadas a Mora y Cañas. Así, en 1970 se celebró en la ciudad el 110 aniversario de la muerte de ambos líderes, con un desfile de las escuelas locales y el Liceo José Martí, que remató en la plaza Mora y Cañas. Estuvieron presentes también el Colegio Patriarca San José (de San Ramón) y el Colegio de Palmares. El programa consistió en las siguientes actividades: enhestadura de la bandera, himno nacional, colocación de una ofrenda floral (por parte de la Escuela Mora y Cañas), acto religioso, palabras del profesor Walter Silva Cruz, Patriótica Costarricense, lectura de la proclama (por el Liceo José Martí), himno a Juan Rafael Mora (por el coro de la Escuela El Carmen) y arreada de la bandera (Walter, 1970, p. 60) ${ }^{21}$. Este vehículo aún persiste y es uno de las conmemoraciones características de la ciudad de Puntarenas. En el año 2011, por ejemplo, "con un gran desfile que abarcó todo el paseo de los Turistas, en que participaron casi 100 bandas provenientes de diferentes provincias del país, los puntarenenses recordaron el 151 aniversario de la muerte de Juan Rafael Mora" (Garita, 2011). Hoy, por diversas razones, la memoria colectiva puntarenense sobre Mora se ha nacionalizado, e incluso, internacionalizado (Vargas Araya, 2014), lo cual resulta paradójico si se considera que Mora era un nacionalista y su figura ha sido adoptada por la memoria oficial en un contexto cada vez más dominado por fuerzas transnacionales y difusas.

\footnotetext{
${ }^{20}$ Según informó el Diario de Costa Rica: "Un numeroso grupo de estudiantes de segunda enseñanza de esta capital estuvo anoche en nuestras oficinas de redacción para pedirnos que publicáramos su inconformidad por la abierta y humillante discriminación de que fueron objeto por parte del Ministerio de Educación, con ocasión del desfile efectuado en Puntarenas en homenaje de los próceres Mora y Cañas.

Es el caso, dijeron, que en tanto a todos los colegios del interior se les obligó a enviar a Puntarenas delegaciones de 25 estudiantes, que naturalmente tuvieron que marchar sin banda, al Liceo Vargas Calvo se le permitió llevar al Puerto su escolta y su banda, es decir, alrededor de 100 estudiantes. Y, de otro lado, en tanto nosotros viajamos en coches corrientes del Ferrocarril, los alumnos del Vargas Calvo viajaron en coche salón" (Inconformidad por discriminación en desfile del Puerto, 1960, p. 11).

${ }^{21}$ Véase también la crítica a este artículo periodístico que planteó Armas Garnier (1970, p. 8).
} 


\section{CONCLUSIONES}

Se ha intentado en el presente artículo un ejercicio de teoría emergente sobre memoria colectiva a partir de la investigación en fuentes primarias (documentales, orales y físicas) como propuesta a ser considerada en la disciplina de la Historia.

El caso de los vehículos de la memoria que se producen y reproducen en la ciudad de Puntarenas nos ha posibilitado plantear algunas ideas básicas para modelizar el estudio de la memoria colectiva como tema historiográfico y la distinción que debe hacerse entre memoria e historia:

1.- La memoria colectiva no es un reflejo fiel del pasado sino su representación desde el presente. En este sentido coincide, sin ser lo mismo, con la historia.

2.- La memoria colectiva cumple un papel naturalizador y, en consecuencia, normativo. Expone una ideología legitimadora del presente construyendo una imagen del pasado.

3.- La exactitud fáctica de la memoria colectiva no es su objetivo principal. Algunos vehículos de memoria sobreviven pero se desligan de los hechos por los cuales se originaron.

4.- Algunos de los vehículos de memoria sobreviven solo como sustrato material, sin poder simbólico alguno y como resultado de path dependency.

5.- El olvido es necesario para la memoria, como herramienta de reconfiguración del pasado y de representación del presente.

6.- Diversas memorias colectivas se pueden superponer, yuxtaponer, reforzar mutuamente o contradecir, creando sincretismos y generando perspectivas, lo que puede generar visiones abigarradas y múltiples de la realidad.

7.- En un mismo vehículo de memoria colectiva pueden confluir diversas representaciones y pretensiones de legitimidad, de distintos grupos.

8.- A una memoria colectiva puede contraponerse una contramemoria, como política de olvido.

9.- Algunas memorias colectivas subsisten, por path dependency, pero su poder simbólico se dirige a naturalizar nuevos contenidos y significados, de construcción reciente, pues la memoria es socialmente construida y dinámica (no se conserva la misma en el tiempo).

10.- La memoria colectiva puede ser construida desde arriba o desde abajo, incluso si usa un mismo vehículo. 
11.- La memoria colectiva un código semántico de memorización y de rememoración.

\section{Referencias}

Algo que podría ser un adorno bellísimo para la población (1915, 29 de julio). El Espartano, p. 4.

Armas Garnier, O. (1970, 8 de octubre). No fue una fiesta. La Nación, p. 8.

Banda de piratas asaltó barco pesquero que zarpaba de Puntarenas (2012, 23 de enero). Repretel.com. http://www.repretel.com/banda-de-piratas-asalt\%C3\%B3-barco-pesquero-que-zarpaba-de-puntarenas.

Carmona, J. D. (1914, 24 de julio). Puntarenas. Señor Director de "El Correo de la Costa". El Correo de la Costa, p. 4.

Carmona, J. D. (1916, 19 de junio). Las fiestas de la Virgen del Mar. El Correo de la Costa, p. 1.

Conmemoración del centenario del fusilamiento de los patricios Mora y Cañas (1960, 3 de junio). La Nación, p. 31 .

Costa Rica. Defeat of Gen. Mora (1860, 16 de octubre). New Orleans Commercial Bulletin, p. 2.

Costa Rica venera la memoria del don Juan Rafael Mora y del General José María Cañas, fusilados en Puntarenas. El primero el día 30 de setiembre de 1860 y el segundo el 2 de octubre de 1860 (1960, 25 de mayo). La Nación, p. 13.

Díaz Arias, D. (2014, 2 de marzo). Juan Rafael Mora Porras en la batalla de la memoria. La Nación. http://www.nacion.com/ocio/artes/Juan-Rafael-Mora-Porras-memoria_0_1399860036.html.

Durán Luzio, J. (Ed.). (2011). Juan Rafael Mora Porras: primer ensayista costarricense, escritos selectos. Costa Rica: Imprenta Lara Segura.

Fallas Santana, C. M. (2004). Elite, negocios y política en Costa Rica, 1849-1859. Alajuela: Museo Histórico Cultural Juan Santamaría.

Fallas Santana, C. M. (2008). La voluntad de la Nación y la regeneración política: Los pronunciamientos militares de 1859, 1868 y 1870 en Costa Rica. Diálogos, 9 (2), 57-76. http://www.historia.fcs.ucr.ac.cr/articulos/2008/vol2/03carmenfallaspronunciamientos.pdf. 
Fernández Guardia, R. (1991). Crónicas coloniales. San José: Editorial Costa Rica.

Festival grandioso (1914, 27 de julio). El Correo de la Costa, p. 1.

Garita, A. (2011, 1 de octubre). Acto por Juan Rafael Mora Porras. La Nación. http://www.nacion.com/nacional/comunidades/Breves-Pais_0_1223277686.html.

Garita, A. (2012, 23 de enero). Piratas asaltan embarcación. Al Día. http://wvw.aldia.cr/ad_ee/2012/enero/23/sucesos3046484.html.

González Vásquez, F. (2010). Mora y Cañas en la toponimia y la estatutaria nacionales. Comunicación 19, 104-111.

González Víquez, C. (1933). El puerto de Puntarenas (Algo de su historia). San José: Imprenta Gutenberg.

González, C. (1960, 1 de octubre). La conmemoración del centenario de Mora y Cañas en Puntarenas. Diario de Costa Rica, p. 14.

Important from Costa Rica (1860, 26 de octubre). Sacramento Daily Union, p. 2.

The New York Times (1860, 8 de octubre de 1860).

Inconformidad por discriminación en desfile del Puerto (1960, 1 de octubre). Diario de Costa Rica, p. 11.

La Virgen del Carmen Patrona del Mar Fiesta Religiosa (1914, 13 de julio). El Correo de la Costa, p. 1.

Las fiestas de la Virgen del Mar (1917, 13 de setiembre). El Viajero, p. 1.

Más cañones (1917, 17 de setiembre). El Viajero, p. 1.

Meléndez Chaverri, C. (Comp.). (1981a). Mensajes presidenciales (Tomo I). San José: Academia de Geografía e Historia de Costa Rica.

Meléndez Chaverri, C. (Comp.). (1981b). Mensajes presidenciales (Tomo II). San José: Academia de Geografía e Historia de Costa Rica.

Panama Star \& Herald (1860, 27 de setiembre). 
Piratas atacaron a pescadores cerca de la Isla Chira de Puntarenas (2008, 10 de octubre). La Nación. http://wvw.nacion.com/ln_ee/2008/octubre/10/sucesos1733243.html.

República de Costa Rica (2010, 16 de agosto). Expediente legislativo No. 17815. AALCR. http://www.asamblea.go.cr/Centro_de_informacion/Archivo/Centro_Dudas/Lists/Formule\%20su\%20pregunta /Attachments/352/PROYECTO\%2017815.doc.

República de Costa Rica (1960, 12 de agosto). Ley No. 2620 (declara el 30 de setiembre de 1960 día feriado). Colección de leyes y decretos, año 1960, semestre 2, tomo 2, 100. También disponible en http://www.pgrweb.go.cr/scij/Busqueda/Normativa/normas/nrm_texto_completo.aspx?param2=1\&nValor1=1 \&nValor2=9372\&nValor3=10040\&nValor4=NO\&strTipM=TC.

Rodríguez, W. (1970, 30 de setiembre). Aniversario de la muerte de Mora y Cañas, hoy. La Nación, p. 60.

Ruiz, F. (1914, 20 de julio). ¡Oh Santa fe, bendita seas! El Correo de la Costa, p. 1.

The Bravery of Two Noted Fillibusters (1860, 30 de octubre). Staunton Spectator, p. 1.

Vargas Araya, A. (2014, 25 de mayo de 2014). Europa y América reconocen a Juan Rafael Mora. La Nación. http://www.nacion.com/ocio/artes/Europa-America-Juan-Rafael-Mora_0_1416658363.html.

10 piratas atemorizan a los pescadores ticos (2012, 25 de enero). Crhoy.com. http://www.crhoy.com/10piratas-atemorizan-a-los-pescadores-ticos/. 